\title{
Undisturbed Switching Control Method of Superheated Steam Temperature Systems
}

\author{
Lei Yu \\ School of Mechanical and Electric Engineering, Soochow University, Suzhou, China \\ Correspondence should be addressed to Lei Yu; yu_lei@suda.edu.cn
}

Received 24 December 2018; Revised 7 March 2019; Accepted 17 April 2019; Published 19 June 2019

Academic Editor: Mojtaba Ahmadieh Khanesar

Copyright (C) 2019 Lei Yu. This is an open access article distributed under the Creative Commons Attribution License, which permits unrestricted use, distribution, and reproduction in any medium, provided the original work is properly cited.

\begin{abstract}
In this paper, a new type of superheated steam temperature switching control system for thermal power plants is presented. A single neuron adaptive PSD (Proportional Sum Differential) predictive controller is designed. The DCS (Distributed Control System) control system platform is used for configuration design. At the same time, the feedforward compensation technology and antiintegration saturation technology are employed to improve the characteristics of large hysteresis and multi-interference in the superheated steam temperature system. Undisturbed switching performance can be well obtained between the new controller and its own PID controller. This proposed method has been well applied in a thermal power plant (600MW) and achieved better control quality.
\end{abstract}

\section{Introduction}

In the operation process of thermal power plants, the superheated steam temperature within the specified range is strictly controlled which has great significance for ensuring the safe and economic operation of the boiler. The thermal power plant boiler is a complex object with nonlinear coupling, large lag, multivariable, and multi-interference. At present, superheated steam temperature control systems of most domestic thermal power plant boiler still use PID controllers, which has many shortcomings in control quality [1-13], such as the lack of timely adjustment and excessive overshoot. Nowadays, many scholars have proposed many advanced control algorithm strategies for boiler superheated steam temperature control systems. In [1], a study of modeling and control of the combustion process in a tangentially fired pulverized-coal boiler was developed to flame geometry and position control by means of reallocation of firing. A minimum entropy based neuro-PID controller is addressed as primary controller in the cascade control system for regulating superheated steam temperature in power plants [2]. In the process of designing the advanced controller, it is easy to be affected by the internal noise disturbance of the control system and the external environment interference, so the system control performance is difficult to achieve the desired effect [3-7]. The system often contains a variety of interference signals and noise. It is often impossible to obtain an effective filtering effect by a single controller, and it is difficult to obtain a better accuracy effect. In addition, the diversified generation method under the actual working conditions determines that the single control algorithm is not ideal for eliminating the disturbance effect [8, 14-18]. Then the researchers proposed a number of integrated control algorithms to improve the accuracy of the system. But the real-time performance of the system is difficult to guarantee. An application of the boiler steam temperature control system has been modeled as the switching control plant, and a disturbance compensator observer from the sliding mode dynamics has been developed to enhance robustness [6]. Therefore, how to ensure the balance between control accuracy and real-time performance of superheated steam temperature systems in thermal power plants is crucial [913]. Inspired by the switching system, this paper introduces the switching rules into the controller design process of the superheated steam temperature system to achieve the undisturbed switching between multiple controllers.

The switching system is a concept in the field of control engineering. "Switching" as an idea was first introduced into 
the control system from the switching servo system $[10,18-$ 21]. It is determined by the switching rule to switch the subsystem, and only one subsystem can work at each moment [14-20]. On the one hand, the proposal and establishment of the switching system theory is adapting to the needs of the development of industrial production practice. On the other hand, it is the inevitable result of the development of control theory itself. The application of the switching control technology realizes the basic problems of the control system and also improves the transient performance of the system and can also meet the needs of the rapid development of intelligent control.

In this paper, inspired by the idea of switching control, the single neuron PSD control with Levinson predictor is successfully applied to the reheat steam temperature control system, and an undisturbed switching scheme is designed. For the self-learning and self-organizing ability of single neurons, the weight of the controller is adjusted online according to the change of the controlled object, while using the predictive control mechanism of Levinson predictor to solve the influence of the large time-delay system for the control performance. In addition, considering the interference and uncertainty of the control object, the Foxboro I/A series DCS control system platform is used for configuration design, and the single neural adaptive PSD predictive control, PID control, and manual control are performed to realize undisturbed switching. The proposed method can improve the control quality of the entire superheated steam temperature switching control system.

\section{Single Neuron Self-Adaptive PSD Predictive Controller Design}

In view of the large delay, time-varying, and uncertainty of the superheated steam temperature control system of the thermal power plant boiler, the main regulator selects the single neuron adaptive PSD prediction controller designed in this paper. The block diagram of the model structure is shown in Figure 1.

As can be seen from Figure 1, the entire control system consists of two main components, a single neuron adaptive PSD controller and a Levinson predictor. The basic idea of the design is that it combines the predictive control idea based on the single neuron adaptive PSD controller, adds a Levinson predictor to predict the output value of the future $d$ step of the system, and uses the predicted value as the feedback amount of the controller. Under the influence of pure lag, the current control law will have an effect on the control object after the pure lag $d$ beat, so predicting the output value of the object after $d$ beat to guide the calculation of the current control law, which can greatly improve the system performance and quick response capabilities.

The specific control algorithm is as follows: Levinson predictor is a method for predicting future output variables based on historical data of output variables [4]. The least squares method is used to select appropriate prediction parameters $a_{i}$ to ensure that the deviation between the predicted values $y_{m}(k+d)$ and actual values $y(k)$ of the advanced $d$ step is minimized. The output of the k-time predictor is

$$
y_{m}(k)=-\sum_{i=1}^{n} a_{i} y(k-i)
$$

Then the predicted value of the $d$ step advance is

$$
\begin{aligned}
y_{m}(k+d \mid k)= & \Psi(k)^{T} \cdot \theta_{i} \\
= & -a_{1} y_{m}(k+d-1 \mid k)-\cdots \\
& -a_{p-1} y_{m}(k+1 \mid k)-a_{p} y(k)-\cdots \\
& -a_{n} y(k+d-n)
\end{aligned}
$$

where $\theta_{i}^{T}=\left(a_{1}, \ldots, a_{p-1}, a_{p}, \ldots, a_{n}\right), \Psi(k)^{T}=\left(-y_{m}(k+\right.$ $\left.d-1 \mid k), \ldots,-y_{m}(k+1 \mid k),-y(k), \ldots,-y(k+d-n)\right)$, and $y_{m}(k+d)$ is the predicted value of the leading $d$ step of the Levinson predictor at time k. $a_{i}(i=1,2, \ldots \mathrm{n})$ are the predictive parameter values which can be determined by least squares estimation: $\hat{\theta}_{i}=\left\{a_{i}\right\}$. $\theta_{i}$ is the coefficient of the least squares estimation. Usually, after retrieving the historical data $\{\mathrm{y}(\mathrm{k}-1), \mathrm{y}(\mathrm{k}-2), \ldots, \mathrm{y}(\mathrm{k}-\mathrm{n})\}$ of system output from the system offline, the optimal prediction parameters are estimated by recursive least squares method:

$$
\hat{\theta}_{i}=\hat{\theta}_{i-1}+\Delta \theta \quad(i=1,2, \ldots, n)
$$

where $\Delta \theta$ is the corrected value for parameter estimation.

Then, the single neuron adaptive control normalization processing is as follows:

$$
\begin{aligned}
u(k) & =u(k-1)+\Delta u(k) \\
\Delta u(k) & =K(k) \cdot F(k)=K(k) \cdot \sum_{i=1}^{3} \omega_{i}^{*}(k) x_{i}(k) \\
\omega_{i}^{*}(k) & =\frac{\omega_{i}(k)}{\sum_{i=1}^{3}\left|\omega_{i}(k)\right|}
\end{aligned}
$$

In (5), $x_{i}(k)$ is the input of controller at time $\mathrm{k}$ :

$$
\begin{aligned}
& x_{1}(k)=e(k)=r(k)-y_{m}(k+d) \\
& x_{2}(k)=\Delta e(k)=e(k)-e(k-1) \\
& x_{3}(k)=\Delta^{2} e(k)=e(k)-2 e(k-1)+e(k-2)
\end{aligned}
$$

where $e(k)$ is the deviation signal, $\Delta e(k)$ is the differential input of the deviation of the controller, $\Delta^{2} e(k)$ is the second differential input of the deviation of the controller, $\omega_{i}(k)$ is the weighting coefficient of the controller parameter, $r(k)$ is the set value of the controlled quantity at time $\mathrm{k}$, and $u(k)$ is the output for controller k-time.

The single neuron adaptive controller realizes the adaptive and self-organizing function by adjusting the weight coefficient $\omega_{i}$. The learning strategy has a great influence on the adaptive ability and stability of the controller. The adjustment of the weight coefficient is implemented based 


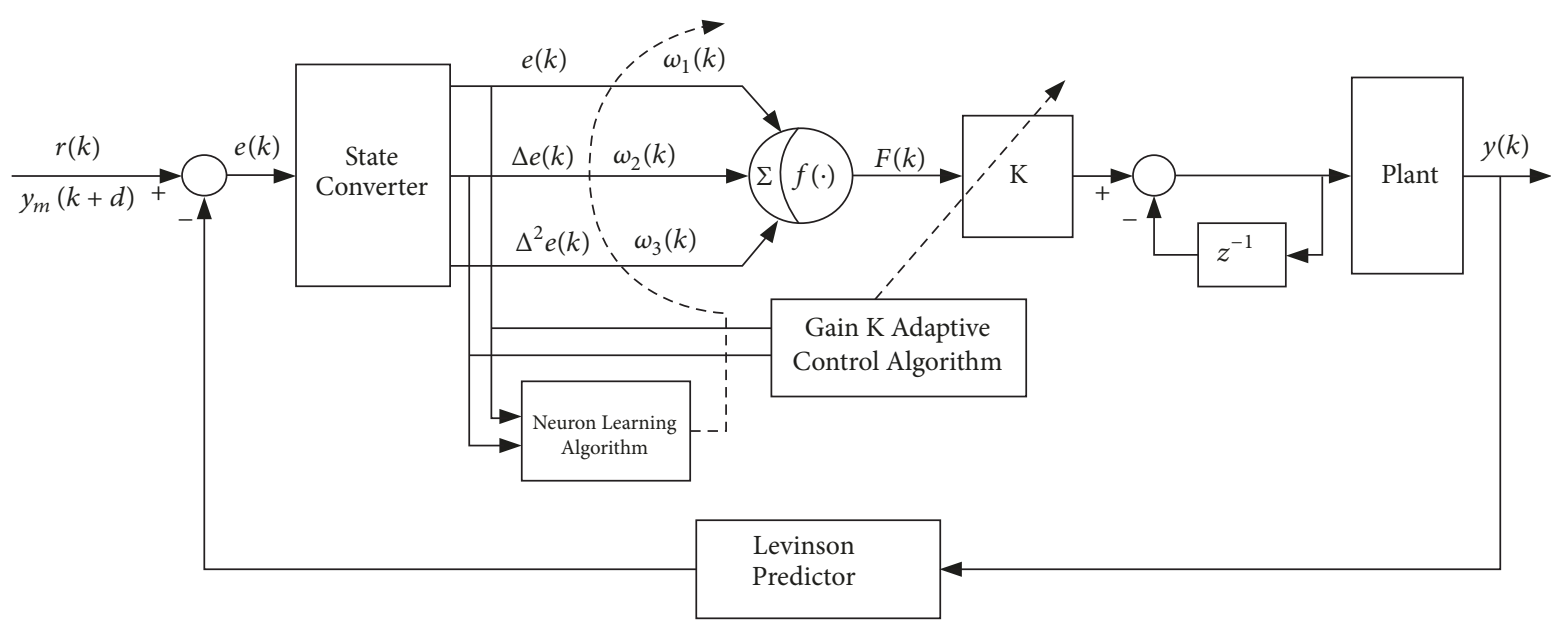

FIGURE 1: The block diagram of the model structure.

on Supervised Hebb learning rules [3, 9-11]. Practice results show that the online learning correction of PSD parameters are mainly related to $\Delta e(k)$ and $\Delta^{2} e(k)$. Therefore, the weighting coefficient learning correction part can be modified, and the improved learning algorithm is

$$
\begin{aligned}
& \omega_{1}(k+1)=\omega_{1}(k)+\eta_{I} e(k) u(k) x_{\delta}(k) \\
& \omega_{2}(k+1)=\omega_{2}(k)+\eta_{P} e(k) u(k) x_{\delta}(k) \\
& \omega_{3}(k+1)=\omega_{3}(k)+\eta_{D} e(k) u(k) x_{\delta}(k)
\end{aligned}
$$

where $x_{\delta}(k)=e(k)+\Delta e(k)=2 e(k)-e(k-1)$; the learning rate $\eta_{P}, \eta_{I}, \eta_{D}$ is preferably selected by the simulation experiment from the integrated time absolute error (ITAE) criterion.

The recursive formula of the gain adaptive $\mathrm{K}(\mathrm{k})$ algorithm is as follows:

$$
K(k)=K(k-1)+\Delta K(k)
$$

$\Delta K(k)$

$$
\begin{aligned}
& =-0.1 \frac{1}{T_{V}(k-1)}\left[\operatorname{Sgn}(e(k)) \cdot \operatorname{Sgn}(\Delta e(k))+h_{r e f}\right] \\
& T_{V}(k-1)=T_{V}(k)-\Delta T_{V}(k) \\
& \Delta T_{V}(k)=L^{*} \cdot \operatorname{Sgn}\left[|\Delta e(k)|-T_{V}(k-1) \cdot\left|\Delta^{2} e(k)\right|\right] \\
& T_{V}(k)=\frac{1}{f_{v}}=\frac{|e(k)|}{\Delta^{2} e(k)}
\end{aligned}
$$

The damping index reference value $h_{\text {ref }}$ is selected as 0.15 by a large number of simulation experiments, which has the best anti-interference performance [4]. $\mathrm{K}(\mathrm{k})$ is the total gain of the controller at time k. $\Delta K(k)$ is the error of the gain adaptive $K(\mathrm{k}) . \Delta T_{V}(k)$ is the recursive incremental error. $f_{v}$ is the coefficient of open loop gain. $L^{*}$ is a real number, $0.05 \leq L^{*} \leq 0.1$.

From the analysis of (9)-(13), the initial value of $K$ is closely related to the stability and rapidity of the system.
The experimental simulation shows that when the initial value of $\mathrm{K}$ is large, the system adjustment time is short, but the response is easy to oscillate, and the overshoot amount becomes larger. When the value is small, the system response is slow and the overshoot is reduced. But when the value is small, the adjustment time becomes larger and the steadystate error increases.

In a summary, the control idea of the entire control system is to use the historical data of the process output and the Levinson predictor to predict the output value of the future $d$ step $(d=\tau / T, \tau$ is the delay time and $\mathrm{T}$ is the sampling period). We use the predicted value as the feedback signal and do the comparison with the set value. The predicted value is defined as the input state variable of the single neuron adaptive PSD control. So the delayed controlled amount is reflected to the controller ahead of time, and the controller moves ahead, which obviously improves the control quality of the large pure hysteresis and large inertia system and obtains the adaptive performance to the time-varying of the system.

\section{DCS Configuration Design with Undisturbed Switching}

3.1. Structure and Characteristics of Superheated Steam Temperature Control System. This paper takes a coal-fired boiler of a $600 \mathrm{MW}$ unit of a thermal power plant as an example to introduce the model structure of the steam temperature system of the modified boiler (Figure 2). The superheater desuperheating water system is a secondary fourpoint desuperheating [6]. The first stage desuperheater is arranged between the low temperature superheater and the partition screen superheater; the second stage desuperheater is arranged between rear screen superheater and final stage superheater. In addition to the influence of the burner swing, the main steam temperature adjustment mainly adopts twostage water spray desuperheating adjustment.

3.2. Configuration Design with Undisturbed Switching Technology. In the actual operation process, it is often necessary to switch between the various control modes. And at the same 


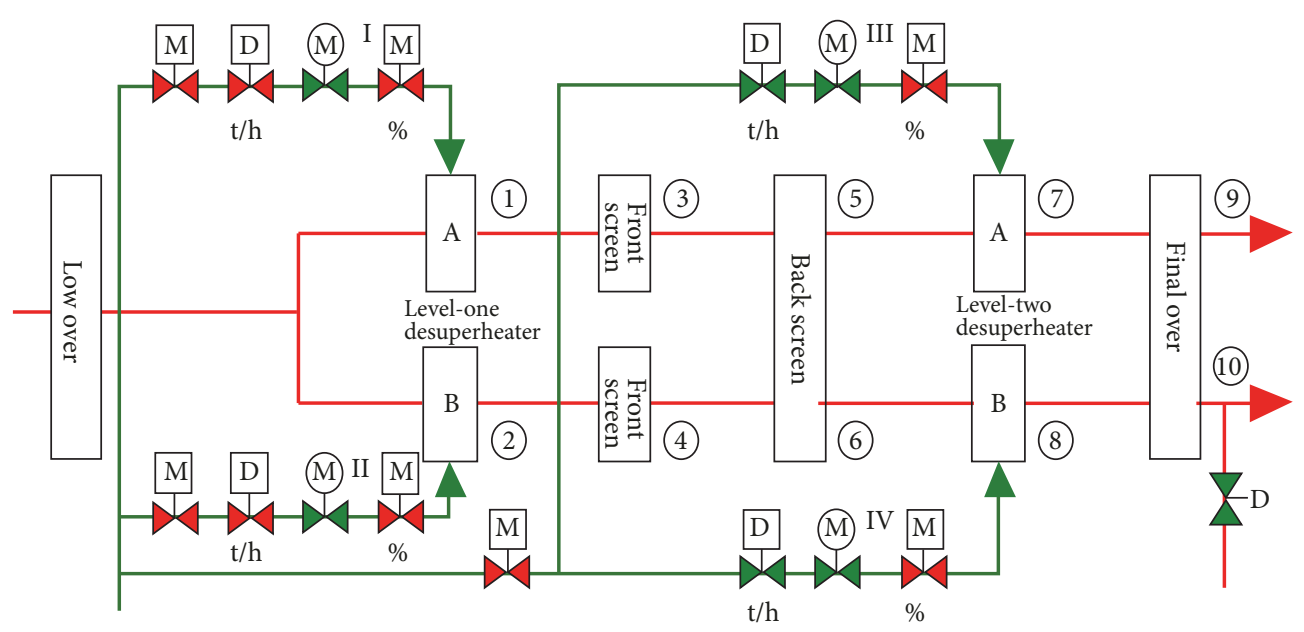

FIGURE 2: Boiler steam temperature system model structure. (Note. The A side of level-one desuperheater is referred to as 1A; the A side of level-two desuperheater is referred to as $2 \mathrm{~A}$; the $\mathrm{B}$ side of level-one desuperheater is referred to as $1 \mathrm{~B}$; the $\mathrm{B}$ side of level-two desuperheater is referred to as $2 \mathrm{~B}$; the $\mathrm{A}$ side of final desuperheater is referred to as final $\mathrm{A}$; the $\mathrm{B}$ side of final desuperheater is referred to as final $\mathrm{B}$.)

time, this operation is not required to have a big impact on the adjustment process; the same requirements are met when changing the controller parameters. The key to achieving undisturbed switching is that the controller output values do not jump large before and after switching. The DCS system of the no. 2 unit of the thermal power plant is a configuration system using the I/A series of Shanghai Foxboro Company. Because the I/A series itself has conventional PID controller, we reserve the secondary loop PID control of the cascade control for the superheated steam temperature control system of the power plant and switch the two control modes between the primary loop PID controller and the single neural adaptive PSD predictive controller.

Aiming at the automatic control engineering transformation of the four sets $(1 \mathrm{~A}, 1 \mathrm{~B}, 2 \mathrm{~A}$, and $2 \mathrm{~B})$ superheated steam temperature control system of the no. 2 unit, the undisturbed switching and feedforward compensation were considered to carry out the DCS configuration. In the case of repeatability, the main design idea of DCS configuration design is given by taking the $1 \mathrm{~B}$ side as an example: the secondary loop PID control of the primary desuperheater is retained, and the outlet temperature of the original primary loop PID controller is controlled by the proposed single neuron adaptive PSD prediction controller. In the case of manual operation, the program tracks the output and control amount of the field operation to avoid large interference and errors when switching to automatic operation, so it can achieve the undisturbed switching between the two modes. Under normal circumstances, manual operation for a period of time makes the control system more steady before switching to the automatic control mode.

For repetitive considerations, only the $1 \mathrm{~B}$ side (Figure 3 ) gives the SAMA (Scientific Apparatus Maker's Association) diagram of its DCS configuration design; other DCS configuration diagrams for $1 \mathrm{~A}$ side, $2 \mathrm{~A}$ side, and $2 \mathrm{~B}$ side are similar for the basic structure. From Figure 3, PSD prediction controller ("PSD module") is the outer loop, and the PID control ("PID2P module") is the inner loop. The secondary

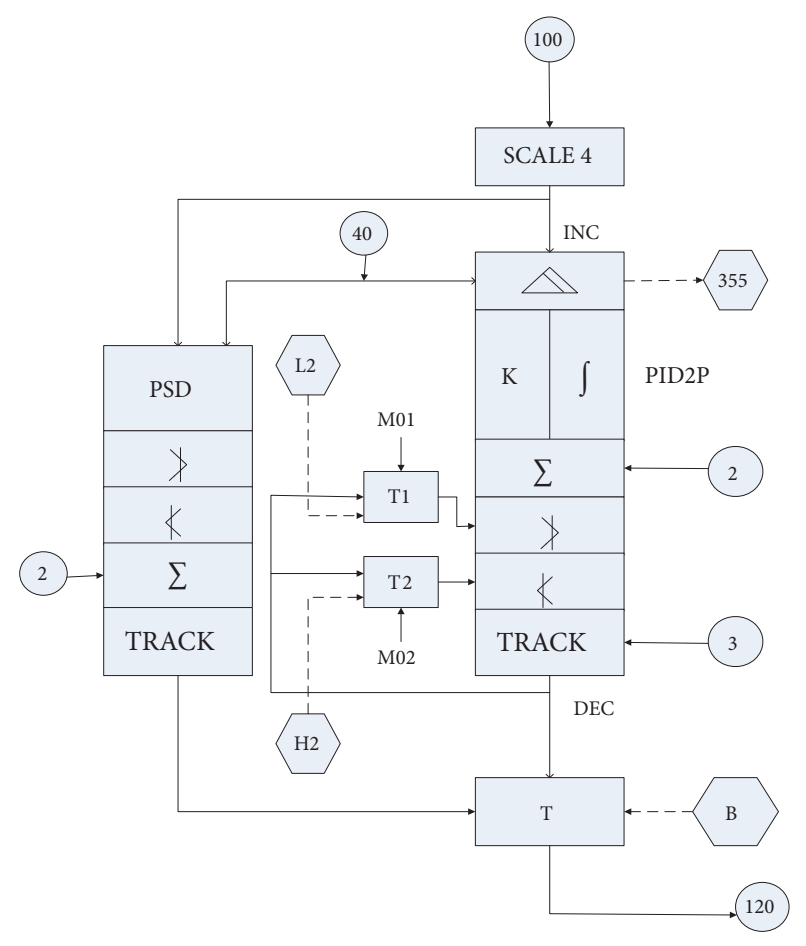

FIGURE 3: SAMA diagram of undisturbed switching configuration design at $1 \mathrm{~B}$ side.

loop PID control of the primary desuperheater is retained, and the single primary neuron adaptive PSD prediction controller ("PSD module") is used to control the outlet temperature on the $\mathrm{B}$ side primary desuperheater of the original primary loop PID control ("PID2P module"). When the B side primary desuperheater is manually operated, the program tracks the output of the $B$ side desuperheater and the primary desuperheater control law to avoid generating large interferences and errors when switching to the automatic operation of the B side primary desuperheater. So this 
configuration design with undisturbed switching technology can be well obtained.

\subsection{Configuration Design with Feedforward Compensation} Technology. Feedforward control is a control strategy that utilizes disturbance signals to improve the performance of the control system fairly economically. In actual operation, there are up to ten impact parameters affecting the main steam temperature, such as steam flow, main steam pressure, total coal volume, E-layer coal volume, F-coal coal volume, swinging nozzle angle, front screen to rear screen guide tube temperature, etc. The feedforward amount considered by the DCS feedforward compensation on the $1 \mathrm{~B}$ side includes the $1 \mathrm{~B}$ desuperheater outlet temperature, the $2 \mathrm{~B}$ desuperheater inlet temperature, the total fuel amount, and the F-coal mill coal amount. Because of the addition of the feedforward compensation signal, the main disturbance factor affecting the process is measured in advance, and then according to the material balance condition, the adjustment amount adapted to the disturbance is calculated and then controlled $[11-13,22]$. Therefore, the control system not only exerts the advantage of timely feedforward control, but also maintains the feedback control to overcome multiple disturbances and has the advantage of performing feedback test on the adjusted amount.

\subsection{Configuration Design with Anti-Integration Saturation} Technology. Since the low water spray desuperheating door is all closed, an effective method to prevent integral saturation is to first cut off the steam temperature automatically and then reinject when the steam temperature rises. However, this will increase the labor intensity of the operating personnel, and the time for casting and cutting will not be well mastered $[21,22]$. Therefore, the following logic is designed: when the subregulator output command reaches the upper and lower limit values (i.e., upper limit value is the maximum value and lower limit value is the minimum value), the input deviation of the main and subregulators is automatically cleared. After the configuration logic is completed, the interface display of the superheated steam temperature control system is configured and displayed the real-time control system temperature, and the manual-automatic switching can be conveniently performed. Also, effectiveness of system parameters should be clearly illustrated, so it is better to extend the current results for the underlying systems under the filter and switching method [23-27].

\section{Simulation Experiment and On-Site Debugging Operation Curve}

The dynamic characteristics of the thermal power plant in the thermal power plant are closely related to the operating conditions of the entire unit. The dynamic characteristics of superheated steam temperature on water spray disturbance were measured by the high temperature superheater of the power plant under four typical loads of $37 \%$ (222MW), $50 \%$ (300MW), 75\% (450MW), and 100\% (600MW). Through a large number of simulations in the laboratory simulation software, the feasibility of the control algorithm is verified and the parameters are optimized. Also, the advanced control platform designed by the laboratory is employed to verify the algorithm. So the single neuron PSD predictive controller of the new thermal power plant superheated steam temperature switching control system can be applicable in engineering.

After a lot of preparations in the early stage (measuring dynamic characteristics, simulation, optimization parameters, DCS configuration, etc.), the undisturbed switching control system designed in this paper was put into trial and debugging operation. The feedforward amount considered by the DCS feedforward compensation on the $2 \mathrm{~B}$ side includes the front screen desuperheater outlet temperature, the $2 \mathrm{~B}$ desuperheater outlet temperature, the final over desuperheater outlet temperature, the total fuel amount, and the Fcoal mill coal amount. After the disturbance is generated, the feedforward control system controls the disturbance according to the size of the disturbance before it is changed. So, feedforward control scheme can compensate the influence of the disturbance on the controlled variable, which can control more timely than the feedback control. When the generator no. 2 generator set (600MW) was steady running at $75 \%$ load $(450 \mathrm{MW}) \pm 30 \mathrm{MW}$, a comparison test was made for the $2 \mathrm{~A}$ side and the $2 \mathrm{~B}$ side. The system simulated time is from 7:00 am to $12: 30 \mathrm{pm}$. The settling time which is defined as the time taken for the transient response to go from the initial (starting) state to the steady-state value is 25 minutes. Figure 4 shows the running curve of the PID control system on the $2 \mathrm{~A}$ side with the DCS platform. Figure 5 shows the running curve of control system on the $2 \mathrm{~B}$ side designed in this paper. The parameters of PID parameters obtained by ITAE criterion are chosen $K=1.35, \eta_{P}=0.40, \eta_{I}=0.35$, and $\eta_{D}=0.35$. Since the valve structures of $2 \mathrm{~A}$ and $2 \mathrm{~B}$ are basically similar, the static and dynamic valve characteristics are the same. By comparing the analysis of Figures 4 and 5 , it can be seen that the deviation of the outlet temperature of $2 \mathrm{~A}$ (Figure 4, curve 4) is steady within $535 \pm 8^{\circ} \mathrm{C}$, and the deviation of the outlet temperature of $2 \mathrm{~B}$ (Figure 5, curve 7) is steady within $535 \pm 4^{\circ} \mathrm{C}$. Therefore, under the condition of the same valve characteristics, the new thermal power plant superheated steam temperature switching control system designed in this paper (Figure 5) is more steady than the own PID control system of the DCS platform (Figure 4), which can fully satisfy the static and dynamic characteristics of superheated steam temperature.

(Note: in Figures 4 and 5, curve 1 indicates the change curve of coal quantity; curve 2 indicates the valve feedback curve; curve 3 indicates the load change curve; curve 4 indicates the outlet temperature curve of $2 \mathrm{~A}$; curve 5 indicates the set value curve; curve 6 represents the end A side outlet temperature curve; curve 7 represents the $2 \mathrm{~B}$ outlet temperature curve; curve 8 represents the end B side outlet temperature curve.)

Through many long-time operation observations, the superheated steam temperature control system based on single neuron adaptive PSD predictive controller is designed in this paper, which is employed to implement automanual switching and undisturbed switching between the controllers. The running results show that the steam temperature under stable load obtains the range of variation within $\pm 4^{\circ} \mathrm{C}$ of the 


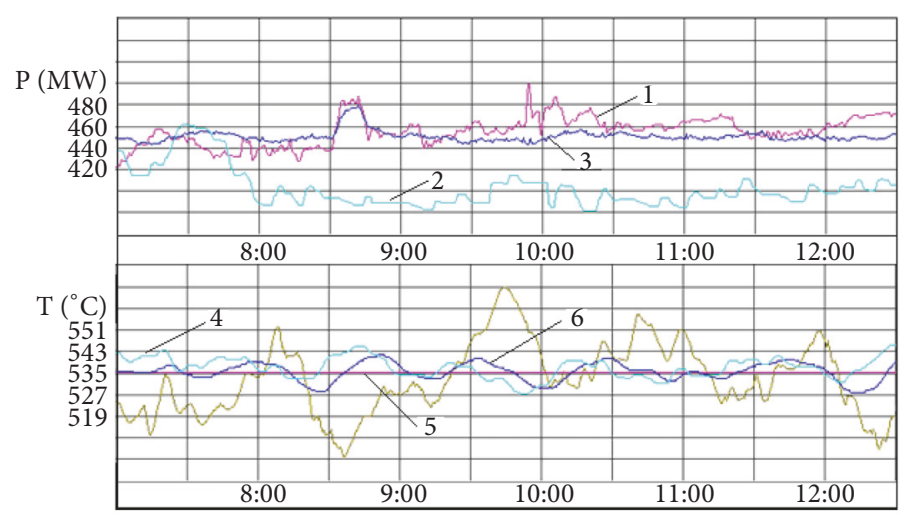

FIgURE 4: The running curve with the PID method at 2A side.

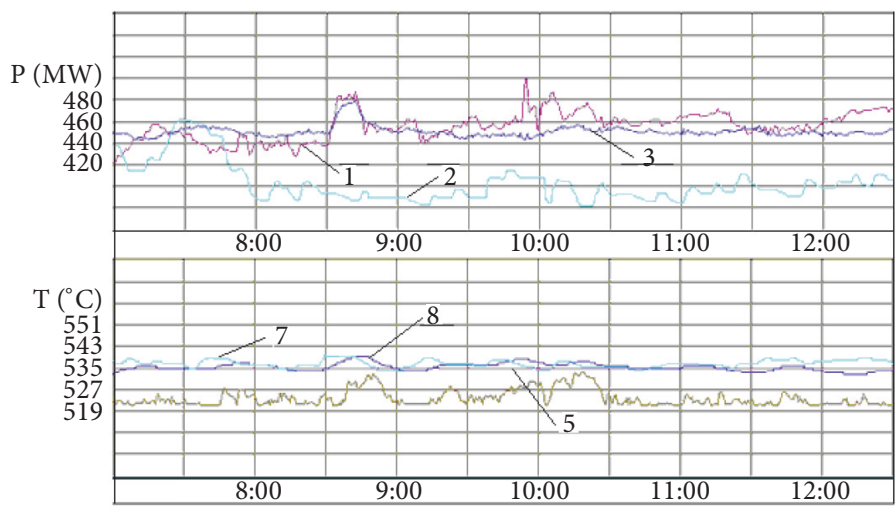

Figure 5: The running curve with undisturbed switching method at 2B side.

set value, and the range under variable load is only within $\pm 7^{\circ} \mathrm{C}$ of the set value. These indexes can satisfy the static index of superheated steam temperature specified by the technical transformation group of the power plant (with a tolerance of $\pm 4^{\circ} \mathrm{C}$ under $70-100 \%$ load) and dynamic index (at 70-100\% load, when the load change rate is $3 \%$, the deviation is within $\left.\pm 8^{\circ} \mathrm{C}\right)$.

Remark 1. The weight of a single neuron can change according to the change of the system, and it can adjust itself according to the changes of the outside world, so it has strong anti-interference performance. It can be seen from the adjustment formula of the weights that the self-adjustment of the weight coefficients has nonlinear approximation ability and therefore has good steady-state performance. The gain coefficient $\mathrm{K}$ of a single neuron is the most sensitive parameter of the system. The single neuron dynamic adjustment process rises smoothly, but the response time is very long. The main reason is that the gain coefficient $\mathrm{K}$ cannot be adjusted online, and the stability and rapidity cannot be achieved.

Remark 2. By comparing with the self-contained control law with cascade controller, the proposed switching control system based on single neuron adaptive PSD predictive controller has the following advantages: (1) The presented method can improve the control characteristics and solve the influence of the large time-delay system for the control performance. (2) Undisturbed switching performance can be well obtained between the new controller and its own PID controller. (3) The feedforward compensation technology and anti-integration saturation technology are employed to improve the characteristics of large hysteresis and multiinterference in the superheated steam temperature system. Therefore, the presented control method is effective and gets better switching control performance than the traditional cascade control method.

\section{Conclusion}

In this paper, a new thermal power plant superheated steam temperature switching control system based on single neuron adaptive PSD predictive controller is developed and applied in a thermal power plant (600MW). The single neuron adaptive PSD control combined with the Levinson predictor is utilized to improve the control characteristics of large lag and multi-interference systems. At the same time, the configuration of the DCS control system platform of Foxboro I/A series is designed, including the undisturbed switching, feedforward compensation, and anti-integration saturation, etc. the presented method can achieve automanual switching and reasonable switching between the controllers. Since the set of superheated steam temperature automatic switching control system has been running steadily, the expected effect 
can be achieved under the normal working condition of stable load or the complicated working condition of variable load, and the control quality can be well obtained. The system is beneficial to improve the control quality of the main steam temperature of the thermal power plant boiler and the automation degree of the power plant operation. Meanwhile, with the undisturbed switching method of superheated steam temperature systems, the economic and safety of the thermal power plant operation can be correspondingly improved and has a high promotion value and application prospect.

\section{Data Availability}

The data used to support the findings of this study are included within the article.

\section{Conflicts of Interest}

The author declares that they have no conflicts of interest.

\section{Acknowledgments}

The work is supported by the National Natural Science Foundation of China (61403268; 61873176); Natural Science Foundation of Jiangsu Province, China (BK20181433).

\section{References}

[1] A. Marjanovic, M. Krstic, Z. Durovic, and B. Kovacevic, "Control of thermal power plant combustion distribution using extremum seeking," IEEE Transactions on Control Systems Technology, vol. 25, no. 5, pp. 1670-1682, 2017.

[2] A. B. Rad, W. L. Lo, and K. M. Tsang, "Simultaneous online identification of rational dynamics and time delay: A correlation-based approach," IEEE Transactions on Control Systems Technology, vol. 11, no. 6, pp. 957-959, 2003.

[3] Z. Dong-yan, L. Ya-qiu, and C. Jun, "Application of single neuron adaptive PID controller during the process of timber drying," Journal of Forestry Research, vol. 14, no. 3, pp. 244-248, 2003.

[4] J. Marsik, "New conception of digital adaptive psd control," Problems of Control and Information Theory, vol. 12, no. 4, pp. 267-277, 1983.

[5] H. Kim, E. K. Kim, J. Kim, K. S. Lee, S. Kim, and Y. Han, "Prediction-based feedforward control of superheated steam temperature of a power plant," International Journal of Electrical Power \& Energy Systems, vol. 71, pp. 351-357, 2015.

[6] L. Yu, C. Zhang, J. Huang, and S. Fei, "Discrete-time slidingmode switching control scheme with disturbance observer and its application to superheated steam temperature systems," Journal of Dynamic Systems, Measurement, and Control, vol. 138, no. 10, pp. 101003-101008, 2016.

[7] G. Liang, W. Li, and Z. Li, "Control of superheated steam temperature in large-capacity generation units based on active disturbance rejection method and distributed control system," Control Engineering Practice, vol. 21, no. 3, pp. 268-285, 2013.

[8] Z. Dong, Z. Zhang, Y. Dong, and X. Huang, "Multi-layer perception based model predictive control for the thermal power of nuclear superheated-steam supply systems," Energy, vol. 151, pp. 116-125, 2018.
[9] S. Zuo, Y. Song, L. Wang, and Z. Zhou, "Neuron-adaptive PID based speed control of SCSG wind turbine system," Abstract and Applied Analysis, vol. 2014, Article ID 376259, 2014.

[10] B. Guo and J. yu, "A single-neuron PID adaptive multicontroller scheme based on RBFNN," Transactions of the Institute of Measurement \& Control, vol. 27, no. 4, pp. 243-259, 2005.

[11] W.-D. Chang, R.-C. Hwang, and J.-G. Hsieh, "A multivariable on-line adaptive PID controller using auto-tuning neurons," Engineering Applications of Artificial Intelligence, vol. 16, no. 1, pp. 57-63, 2003.

[12] Y. Wang, Q. Jin, and R. Zhang, "Improved fuzzy PID controller design using predictive functional control structure," ISA Transactions, vol. 71, pp. 354-363, 2017.

[13] Y. Wang, R. Rajamani, and A. Zemouche, "A quadratic matrix inequality based PID controller design for LPV systems," Systems Control Letters, vol. 126, pp. 67-76, 2019.

[14] L. Zhu and Z. Xiang, "Aggregation analysis for competitive multiagent systems with saddle points via switching strategies," IEEE Transactions on Neural Networks and Learning Systems, vol. 29, no. 7, pp. 2931-2943, 2018.

[15] G. Zong, R. Wang, W. Zheng, and L. Hou, "Finite-time $\mathrm{H}_{\infty}$ control for discrete-time switched nonlinear systems with time delay," International Journal of Robust and Nonlinear Control, vol. 25, no. 6, pp. 914-936, 2015.

[16] L. Yu, C. Li, and S. Fei, "Any-wall touch control system with switching filter based on 3-D sensor," IEEE Sensors Journal, vol. 18, no. 11, pp. 4697-4703, 2018.

[17] J. Yu, J. Zhuang, and D. Yu, "State feedback integral control for a rotary direct drive servo valve using a Lyapunov function approach," ISA Transactions, vol. 54, pp. 207-217, 2015.

[18] Z. Sun and S. S. Ge, "Analysis and synthesis of switched linear control systems," Automatica, vol. 41, no. 2, pp. 181-195, 2005.

[19] M. S. Branicky, "Multiple Lyapunov functions and other analysis tools for switched and hybrid systems," IEEE Transactions on Automatic Control, vol. 43, no. 4, pp. 475-482, 1998.

[20] J. Mao, Z. Xiang, G. Zhai, and J. Guo, "Adaptive practical stabilization of a class of uncertain nonlinear systems via sampled-data control," Nonlinear Dynamics, vol. 92, no. 4, pp. 1679-1694, 2018.

[21] J. Xu, Y. Zhao, Z. Jia, and J. Zhang, "Rotor dynamic balancing control method based on fuzzy auto-tuning single neuron PID," IEICE Electronics Express, vol. 14, no. 10, Article ID 20170130, 2017.

[22] T. Wakui, M. Yoshimura, and R. Yokoyama, "Multiple-feedback control of power output and platform pitching motion for a floating offshore wind turbine-generator system," Energy, vol. 141, pp. 563-578, 2017.

[23] L. Yu, J. Huang, and S. Fei, "Robust switching control of the direct-drive servo control systems based on disturbance observer for switching gain reduction," IEEE Transactions on Circuits and Systems II: Express Briefs, p. 1, 2018.

[24] L. Yu and J. Hou, "Large-Screen interactive imaging system with switching federated filter method based on 3d sensor," Complexity, vol. 2018, Article ID 8730281, 11 pages, 2018.

[25] J. Hou, L. Yu, and S. Fei, "Four-point trapezoidal calibration algorithm for human-computer interaction system based on 3D sensor," Measurement, vol. 134, pp. 730-738, 2019. 
[26] L. Yu, "Image noise preprocessing of interactive projection system based on switching filtering scheme," Complexity, vol. 2018, Article ID 1258306, 10 pages, 2018.

[27] D. Cheng, C. Li, X. Zhang, and F. He, "Controllability of boolean networks via mixed controls," IEEE Control Systems Letters, vol. 2, no. 2, pp. 254-259, 2018. 


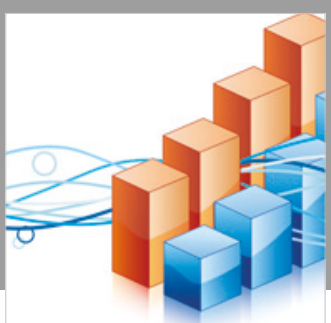

Advances in

Operations Research

\section{-n-m}
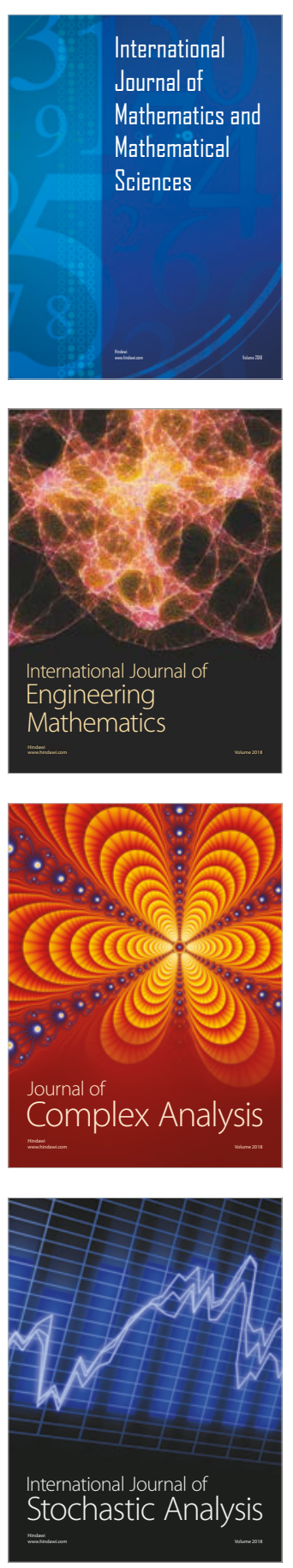
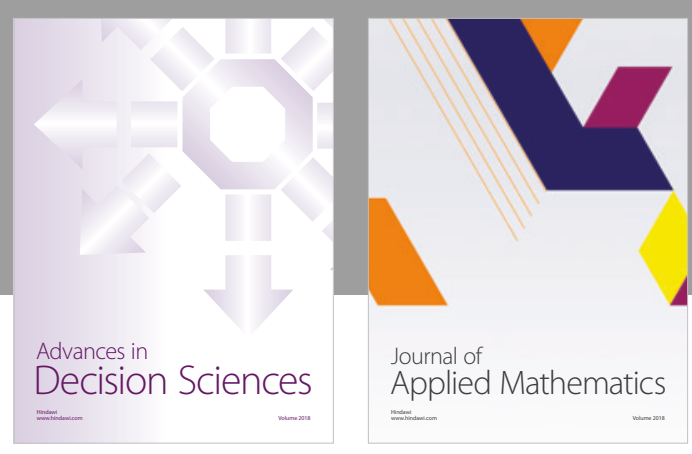

Journal of

Applied Mathematics
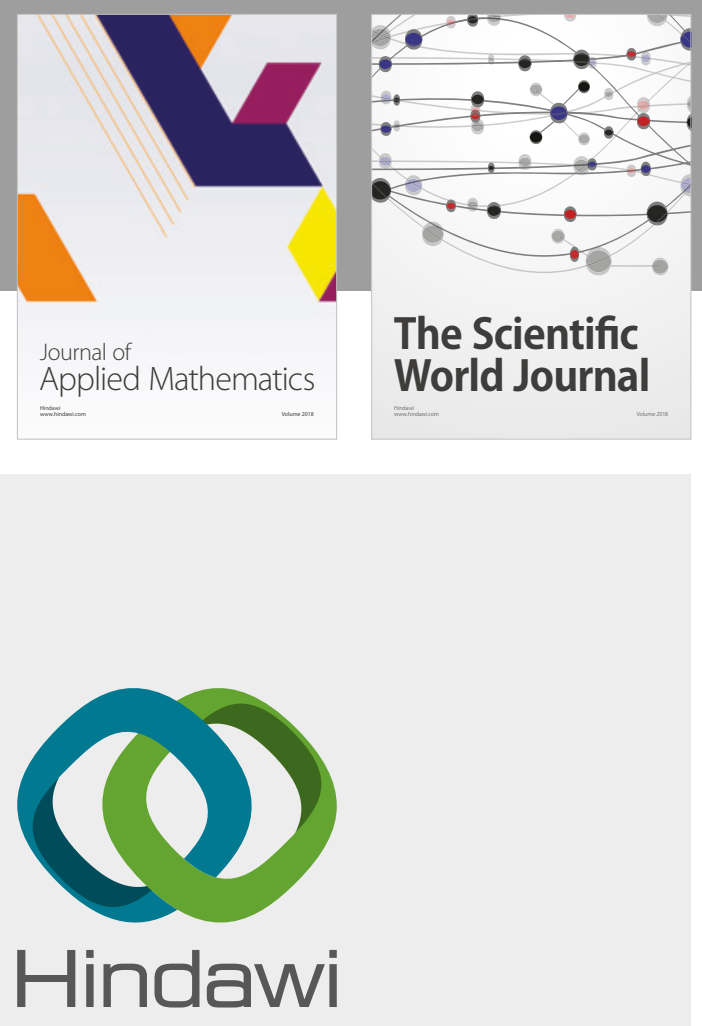

Submit your manuscripts at

www.hindawi.com

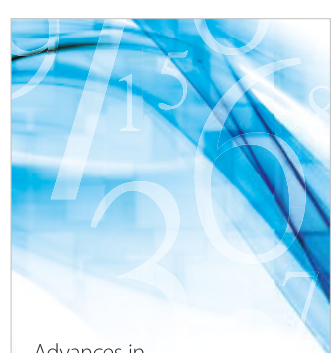

Advances in
Numerical Analysis
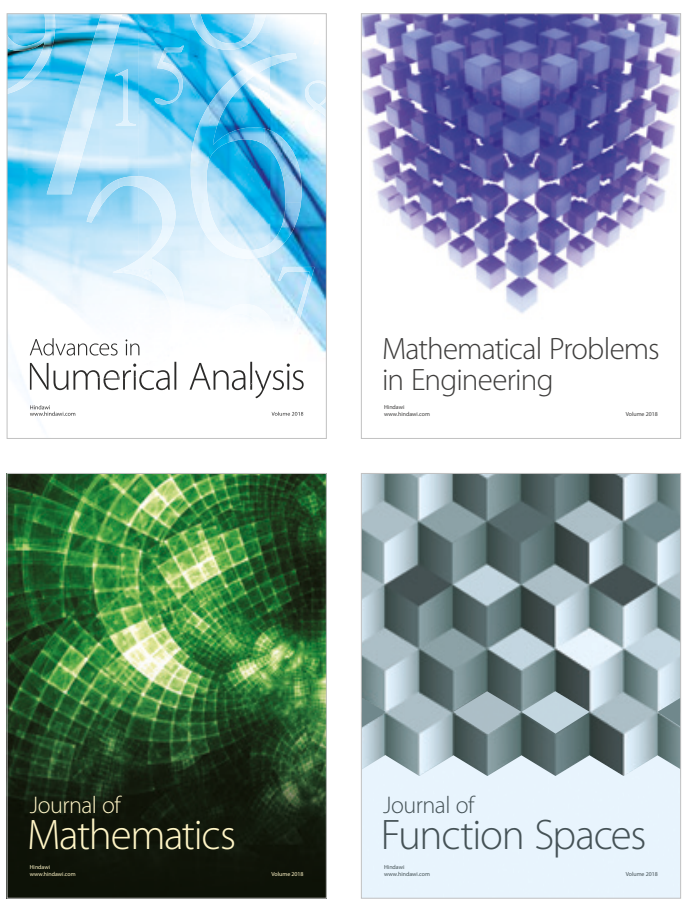

Mathematical Problems in Engineering

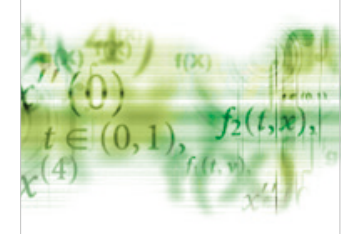

International Journal of

Differential Equations

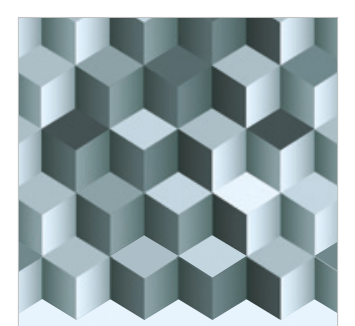

Journal of

Function Spaces
The Scientific

World Journal

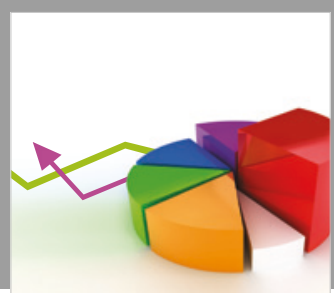

Journal of

Probability and Statistics
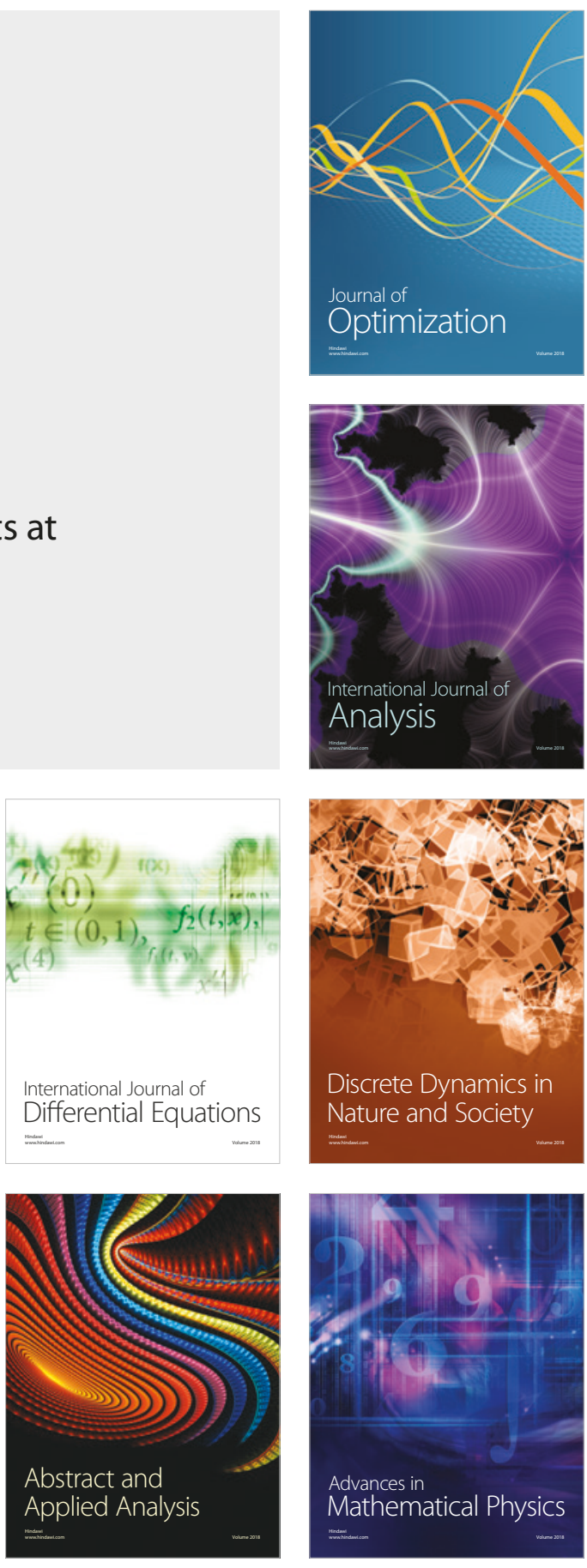